\title{
ACOUSTIC EMISSION MONITORING OF TEXTILE REINFORCED CEMENT PLATES
}

Eleni Tsangouri ${ }^{1}$, Aymeric Hardy², Aron Van Driessche ${ }^{1}$, Amir Si Larbi², Dimitrios Aggelis ${ }^{1}$

${ }^{1}$ Dept. Mechanics of Materials \& Constructions (MeMC), Vrije Universiteit Brussel (VUB), Belgium

2Univ Lyon, Ecole Nationale d'Ingénieurs de Saint-Etienne (ENISE), Laboratoire de Tribologie et de Dynamique des Systèmes (LTDS), UMR 5513, 58 Rue Jean Parot, 42023 Saint-Etienne Cedex 2, France

VRIJE

UNIVERSITEIT BRUSSEL 


\section{INTRODUCTION}

Textile Reinforced Cement is a sustainable and lightweight alternative of concrete
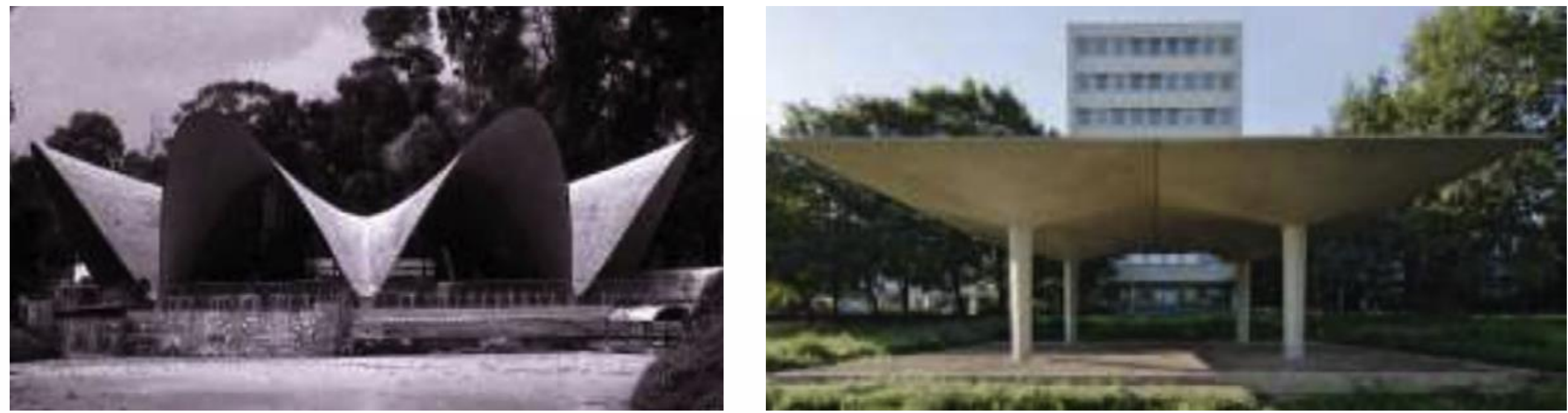

While it exhibits certain advantages, its mechanical and fracture behavior needs to be studied. Along with the possibility to monitor its structural condition.

Developments in the Built Environment, https://doi.org/10.1016/j.dibe.2020.100013 


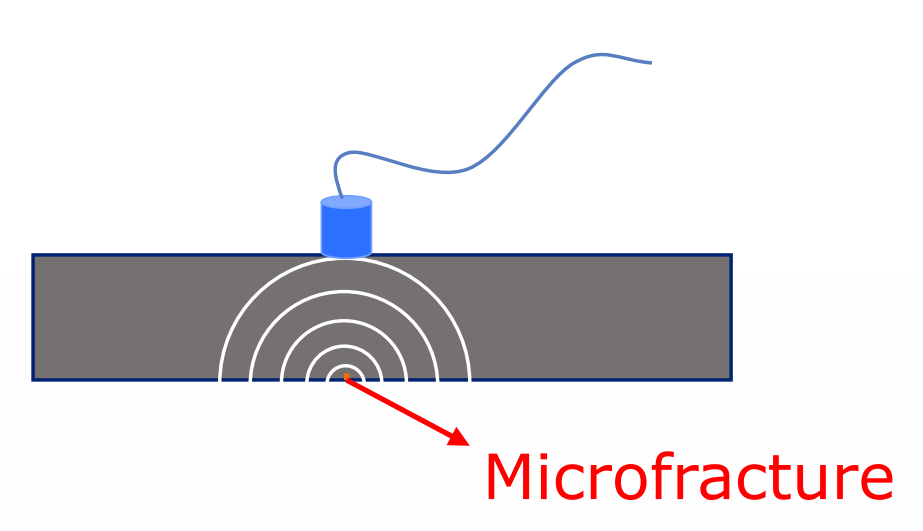

- Average Frequency (AF)

- Duration

- Rise Time (RT)

- Amplitude

- RA value
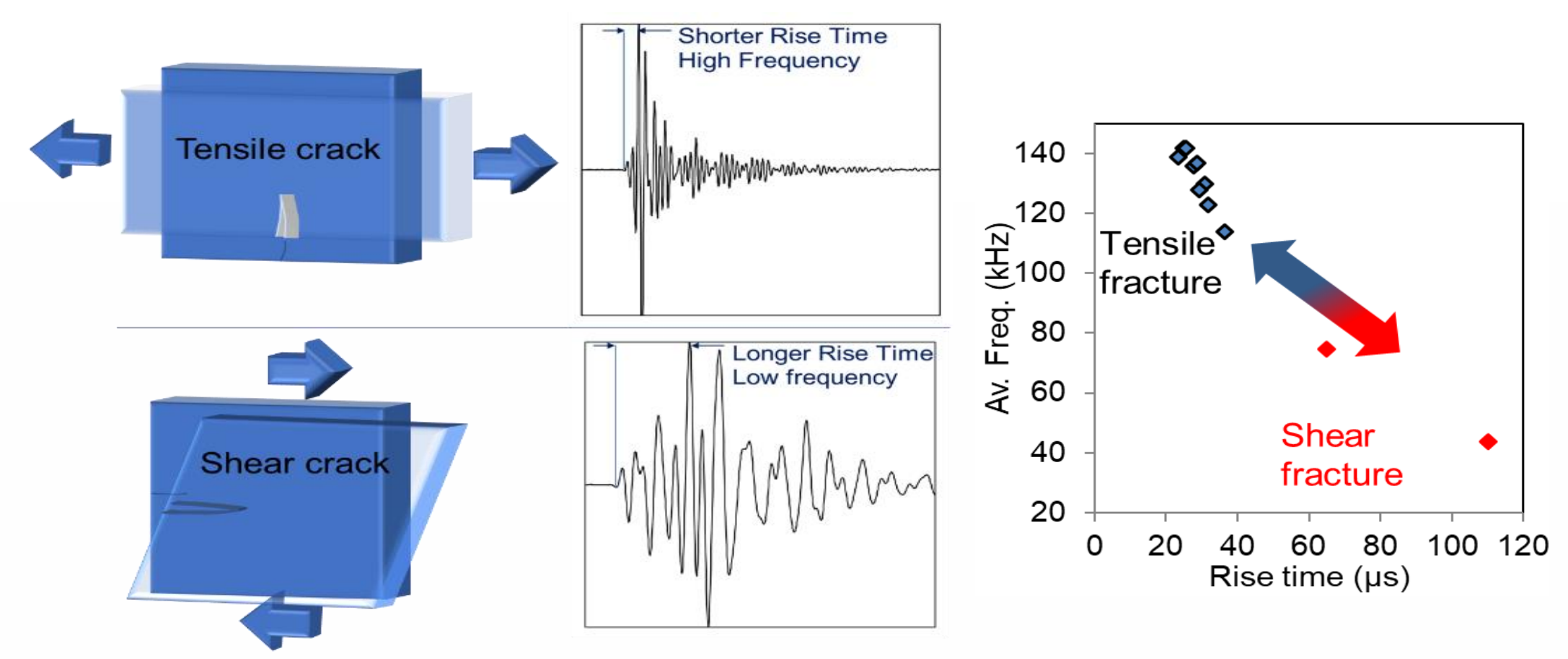


\section{ACOUSTIC EMISSION}

\section{PROBLEM STATEMENT}

Frequency content and waveform shape are severely distorted due to:

- Scattering

- Damping

- Reflections

- Wave dispersion

- Geometry (curvature, width, dimensions of the member)

Consequence: sensors at different distances will receive different waveforms

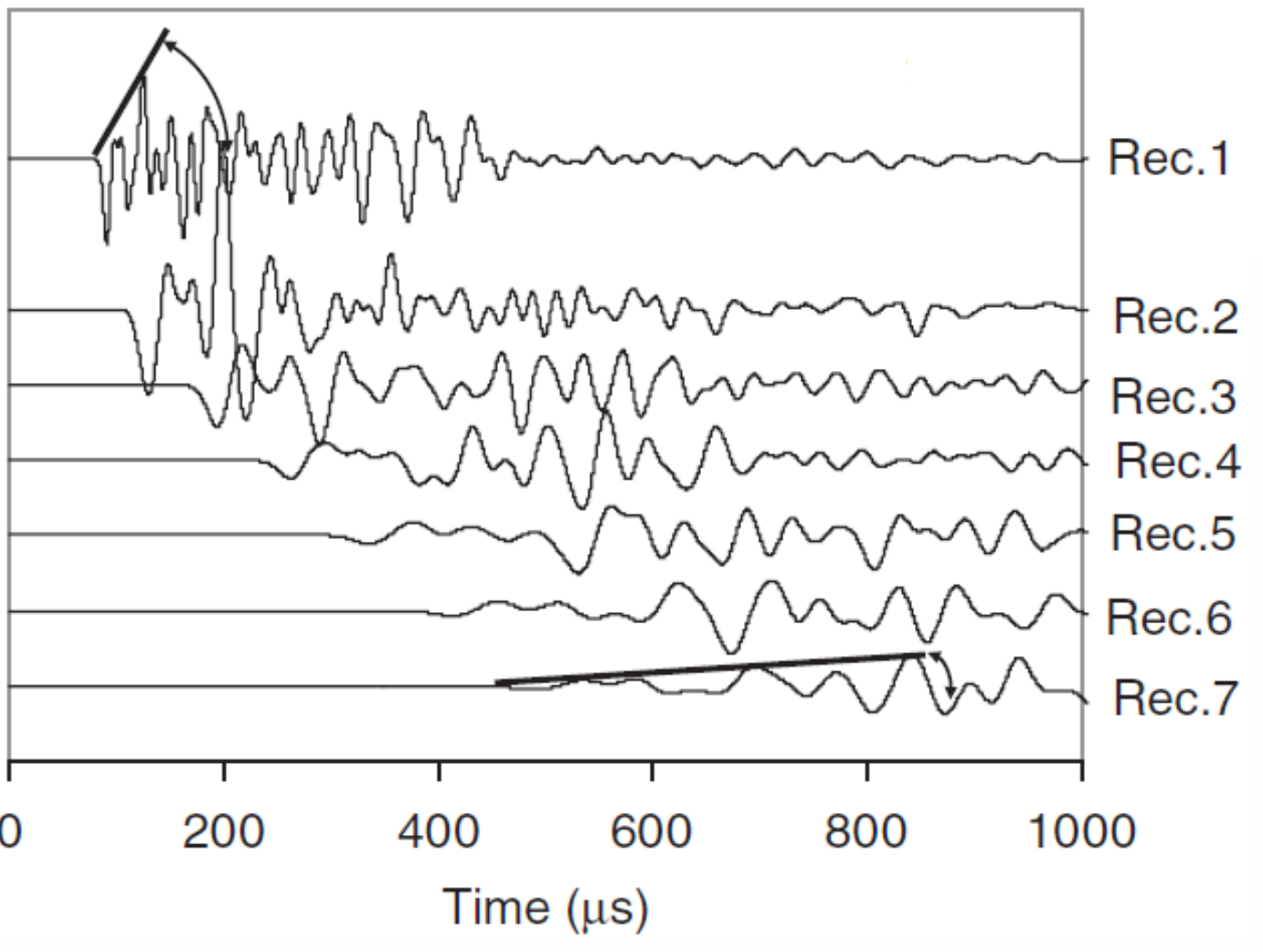

different widths.

DOI: $10.1177 / 1475921711419992 s h m . s a g e p u b . c o m$ 


\section{EXPERIMENTAL DETAILS}

\section{MATERIALS}

\section{Textile Reinforced Inorganic Phosphate Cement}

Reinforcement: E-glass chopped fiber mats $\left(300 \mathrm{~g} / \mathrm{m}^{2}\right)$

Fiber volume fraction: $20 \%$
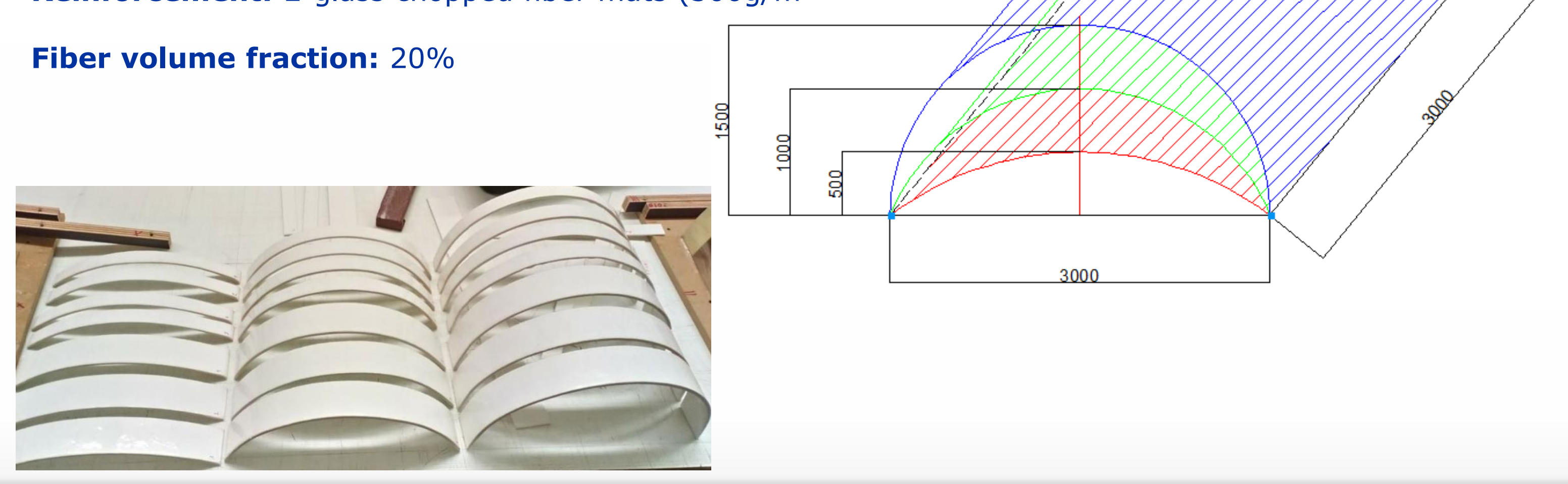


\section{MECHANICAL EXPERIMENTS WITH AE}

- 3P bending

- R15 AE sensors

- Micro-II Digital AE System

- Pencil lead break excitation

- Propagation speed: $2730 \mathrm{~m} / \mathrm{s}$

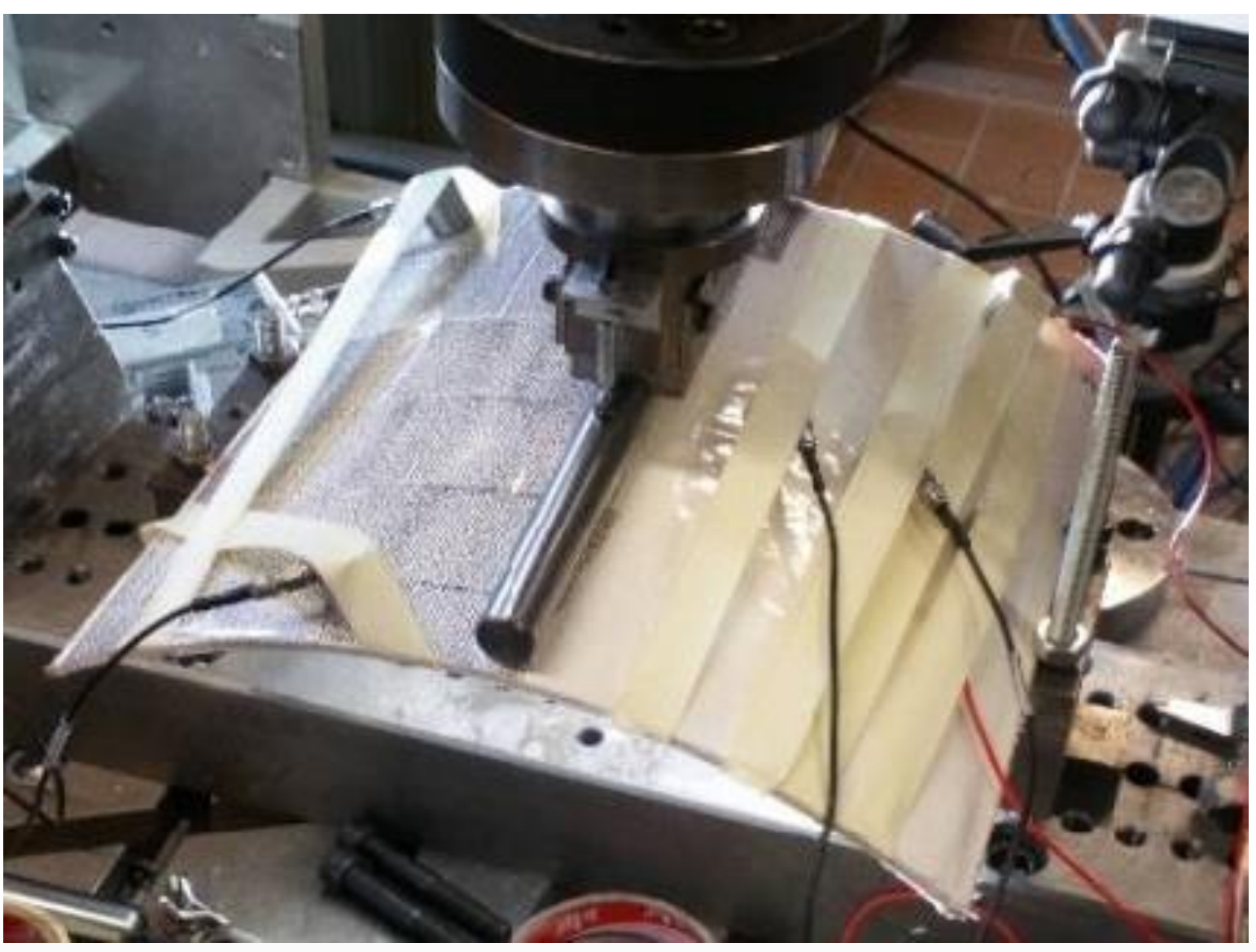




\section{RESULTS}

\section{DIGITAL IMAGE CORRELATION}

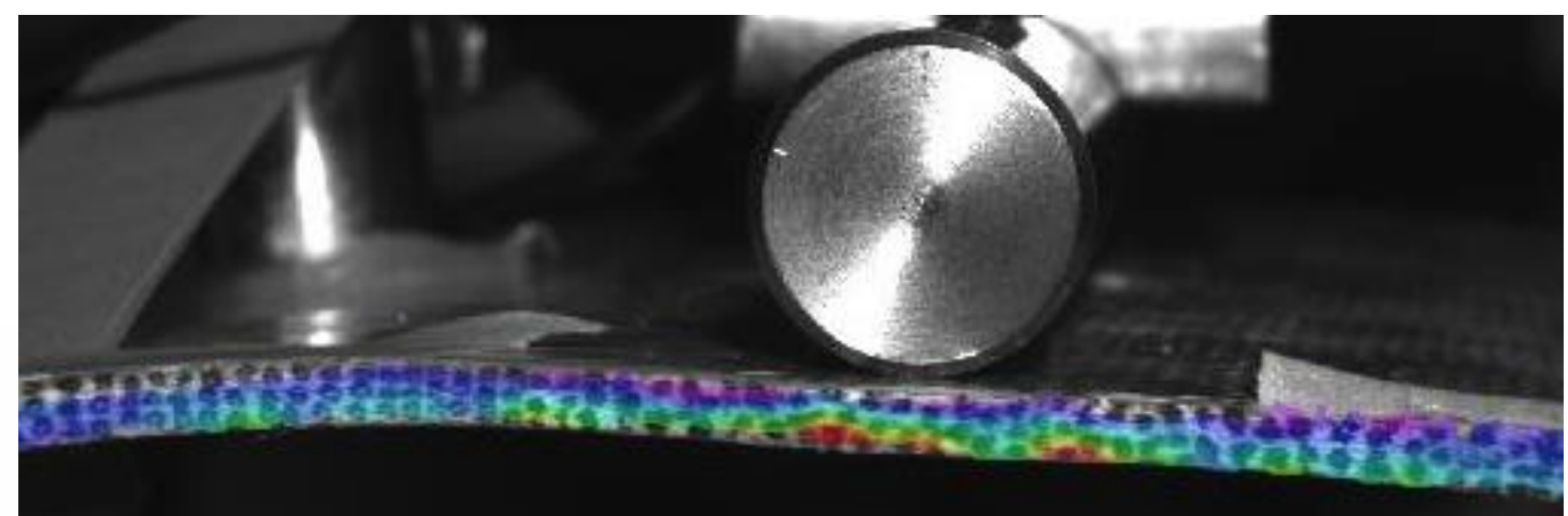

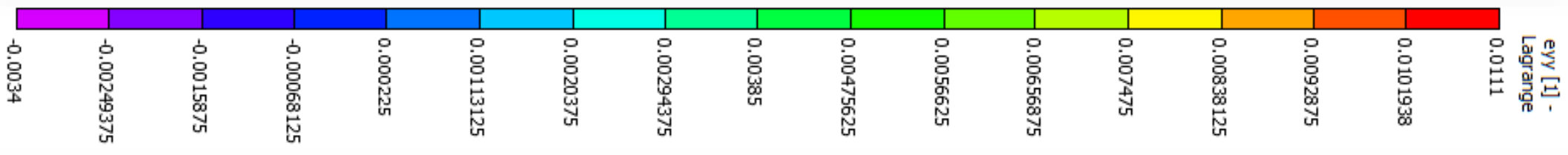

The strain field was calculated by DIC. This helps in the interpretation of AE signals 


\section{RESULTS}

\section{LOAD AND ACOUSTIC EMISSION - 5 CM BEAM}
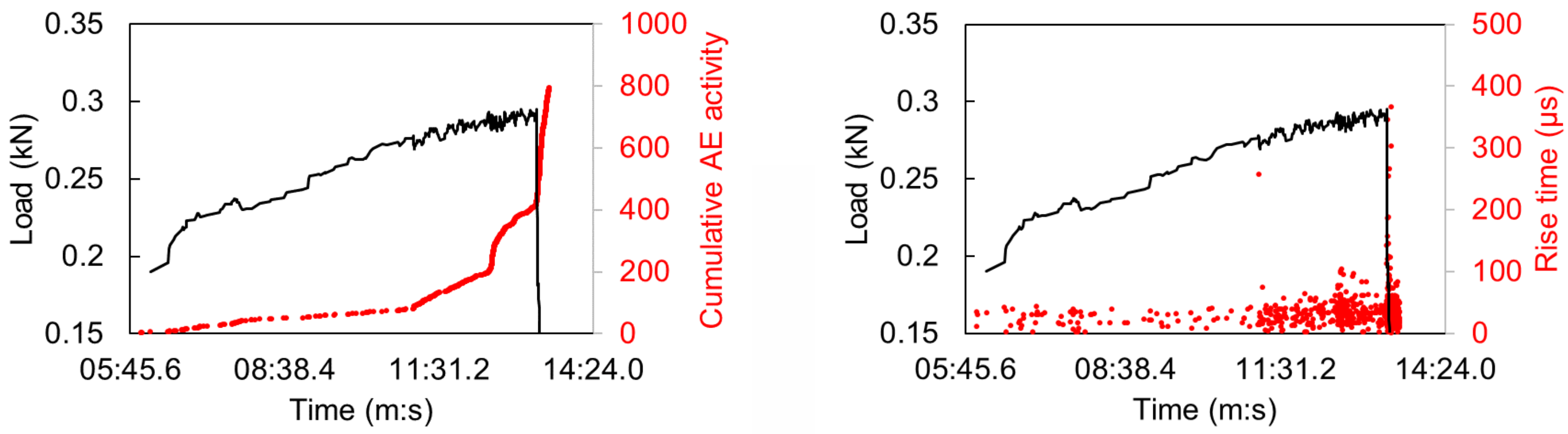

$\mathrm{AE}$ increases as the load reaches its maximum.

AE RT increases gradually signifying the shift from matrix cracking to delaminations, while at the macroscopic failure the values are the highest. 


\section{RESULTS}

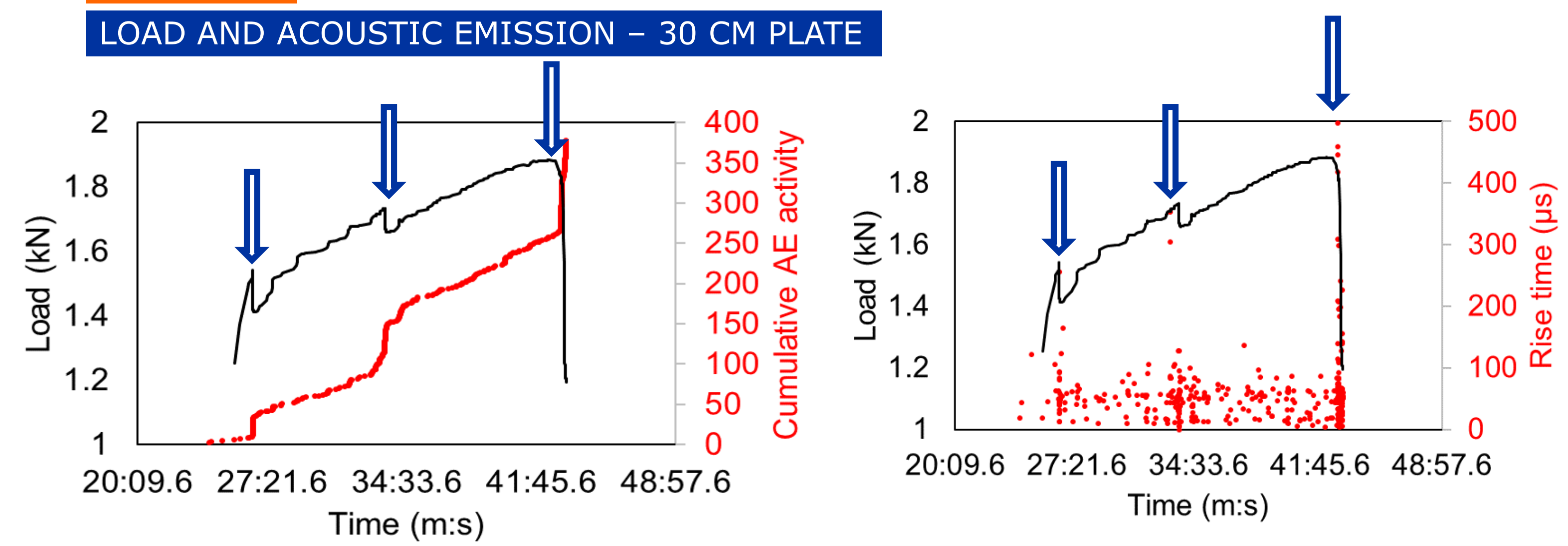

Transient load drops are escorted by AE increasing rate, while at the same time, higher RT values are exhibited. 


\section{RESULTS}

\section{AE PARAMETERS (RISE TIME) VS. SPECIMEN WIDTH}

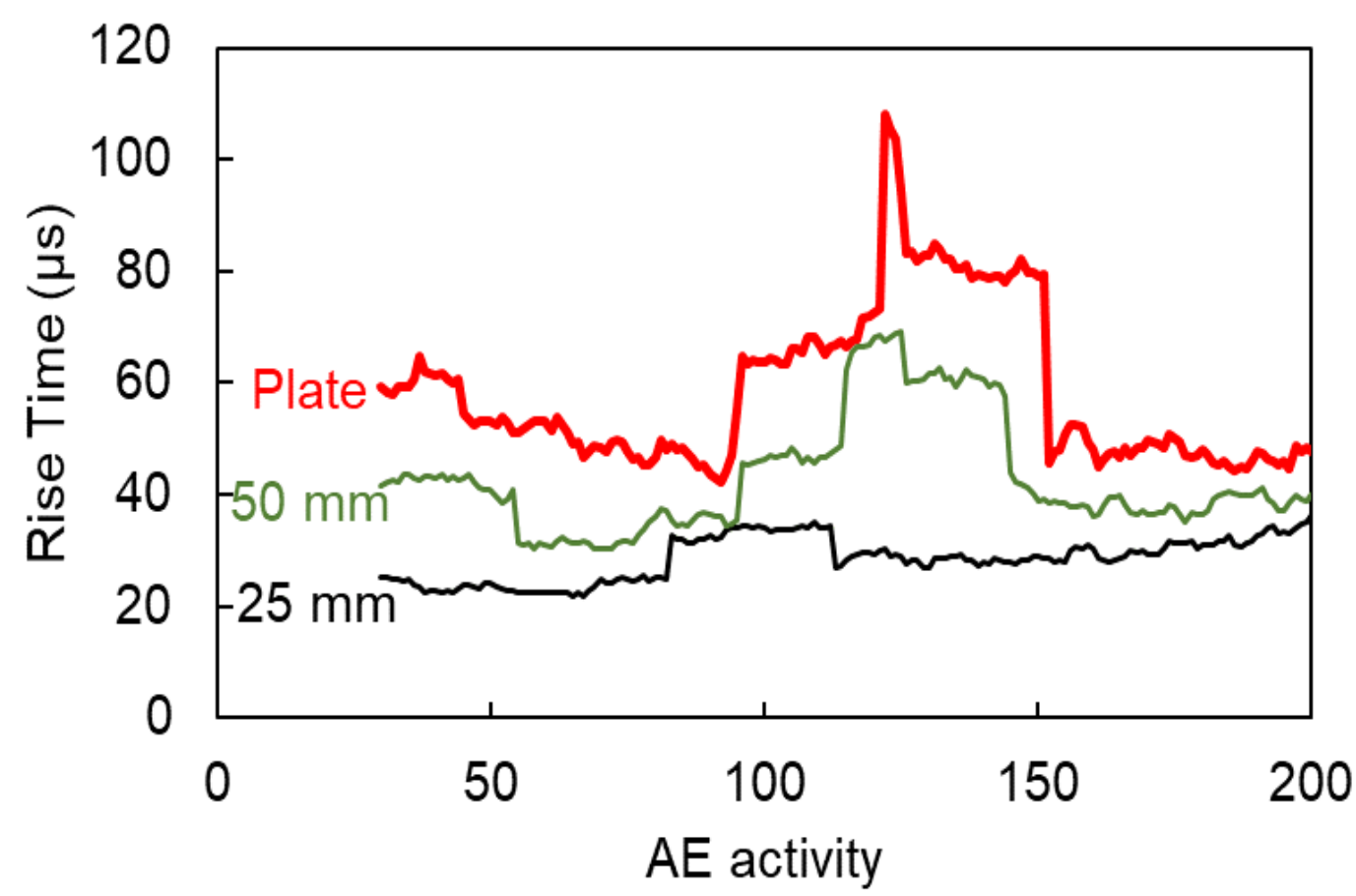

While the general trends are similar for all different specimens, there are consistent differences relatively to the vertical dimension of the specimens.

Thin beams show the lowest rise time, while the wider plate exhibits the longest.

This shows the strong effect of dimensions on the $A E$ signature, even though the dominant damage mechanism remains the same. 


\section{RESULTS}

\section{AE PARAMETERS (AVERAGE FREQUENCY) VS. SPECIMEN WIDTH}

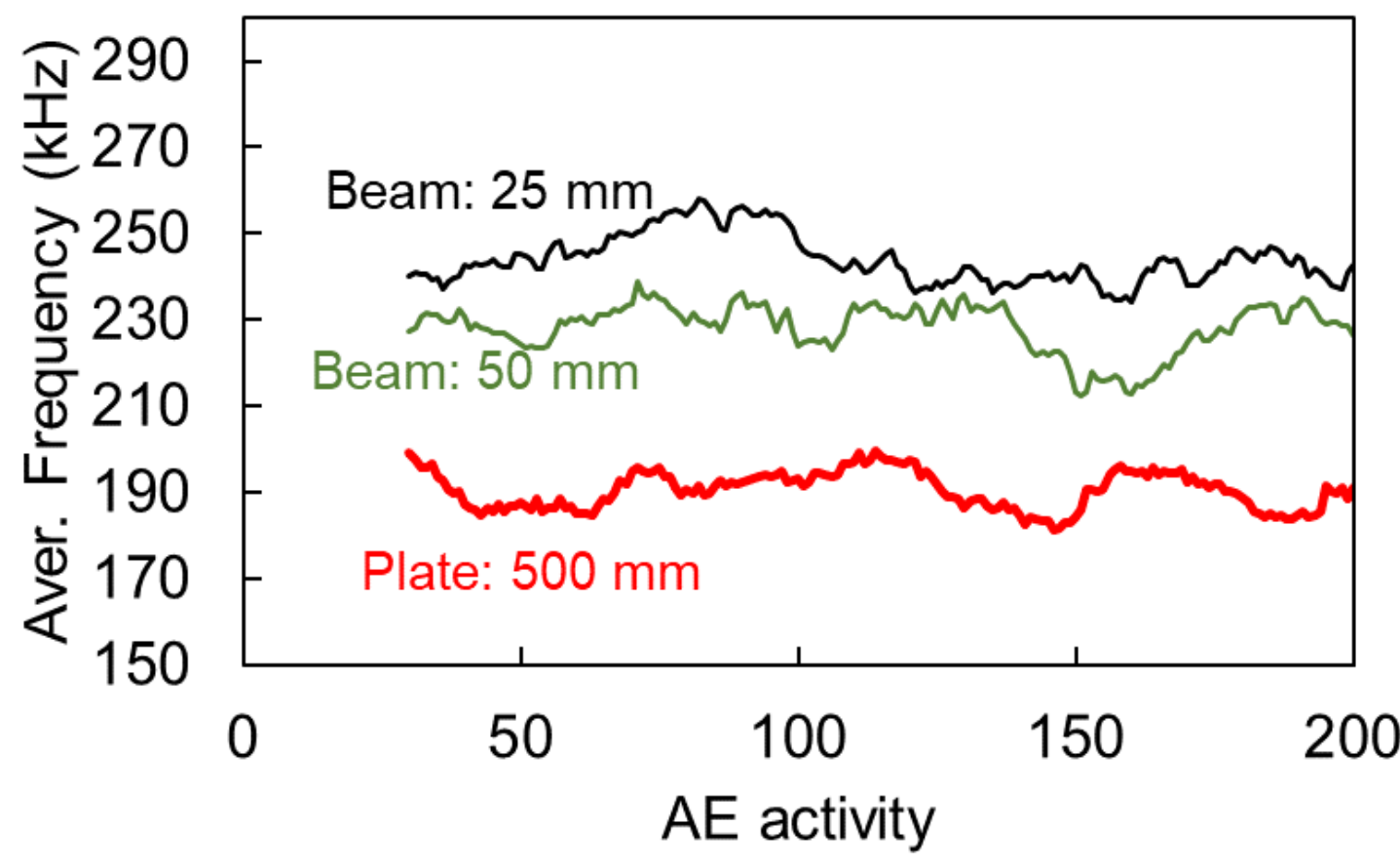

Thin beams show the highest $A F$, while the wider plate exhibits the longest.

This shows the strong effect of dimensions on the AE signature, even though the dominant damage mechanism remains the same.

AE activity 


\section{RESULTS}

\section{AE PARAMETERS (AVERAGE FREQUENCY) VS. SPECIMEN WIDTH}

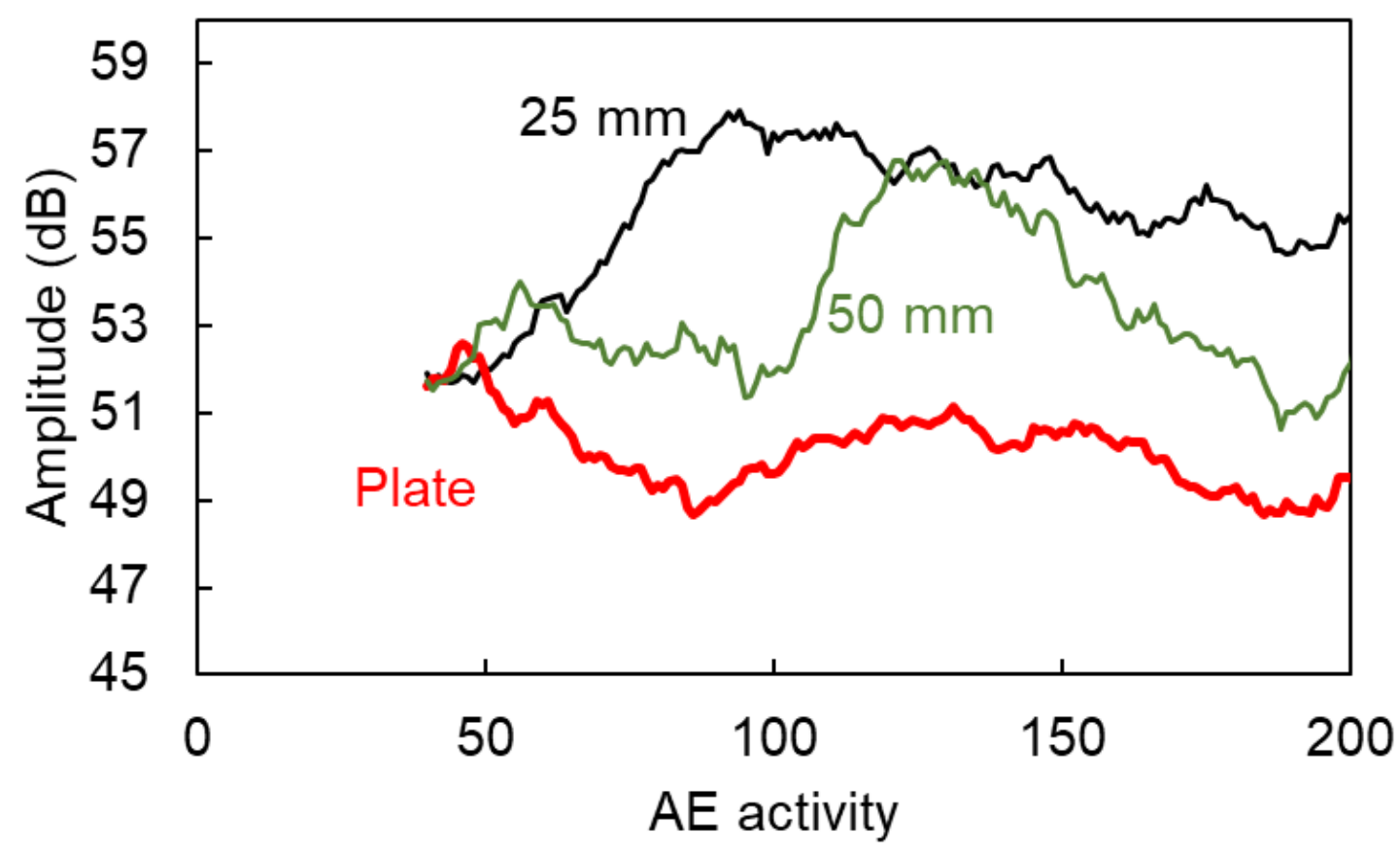

Thin beams show higher Amplitude, while the wider plate exhibits the lowest.

The reason can be sought in the 2D spreading of the wave energy in the case of the plate, something that is limited in the thin beams. 


\section{RESULTS}

\section{CRACK CLASSIFICATION BASED ON THE AE PARAMETERS}

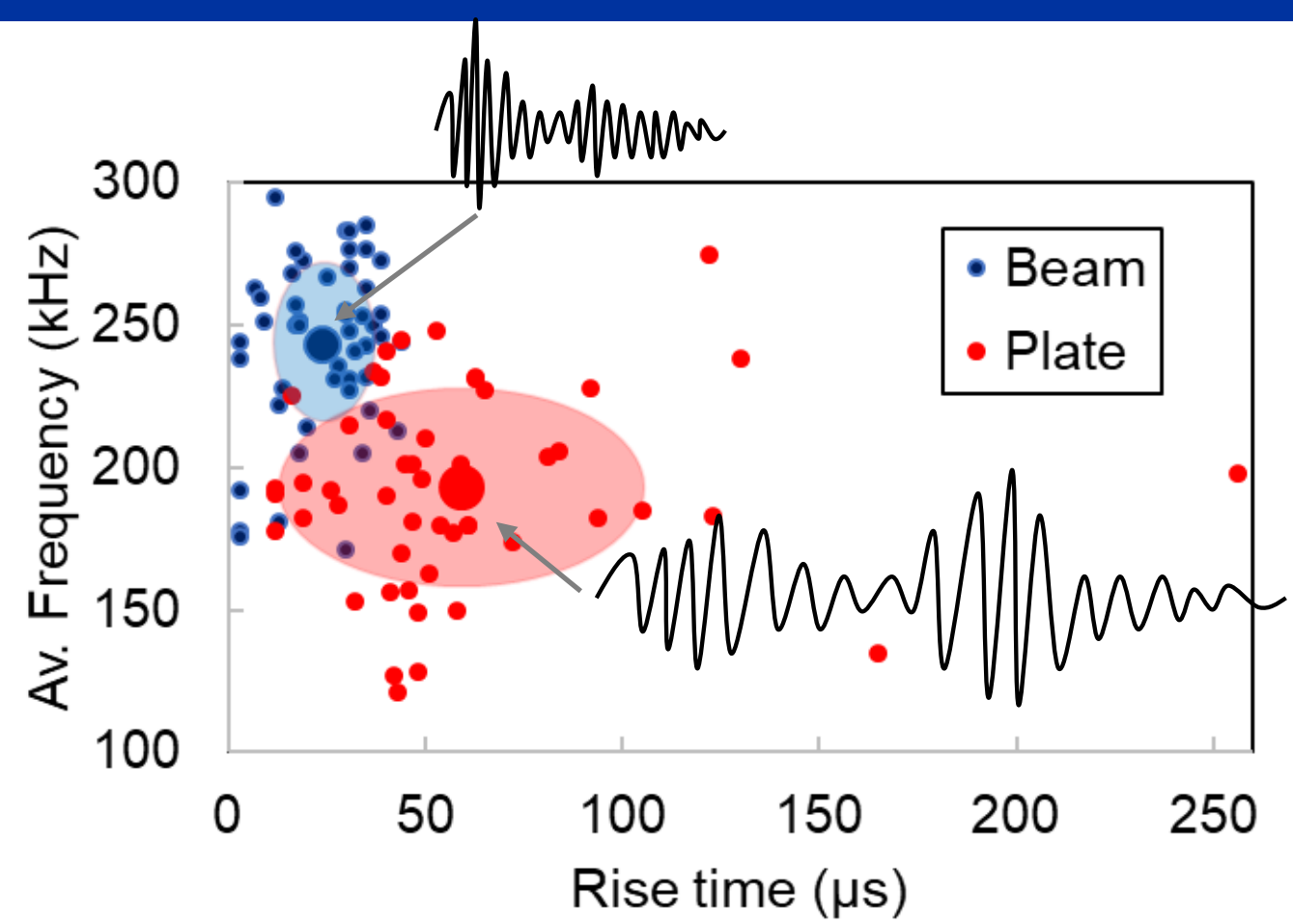

AE data coming from the same mechanism (matrix cracking) show much different values depending on the specimen size.

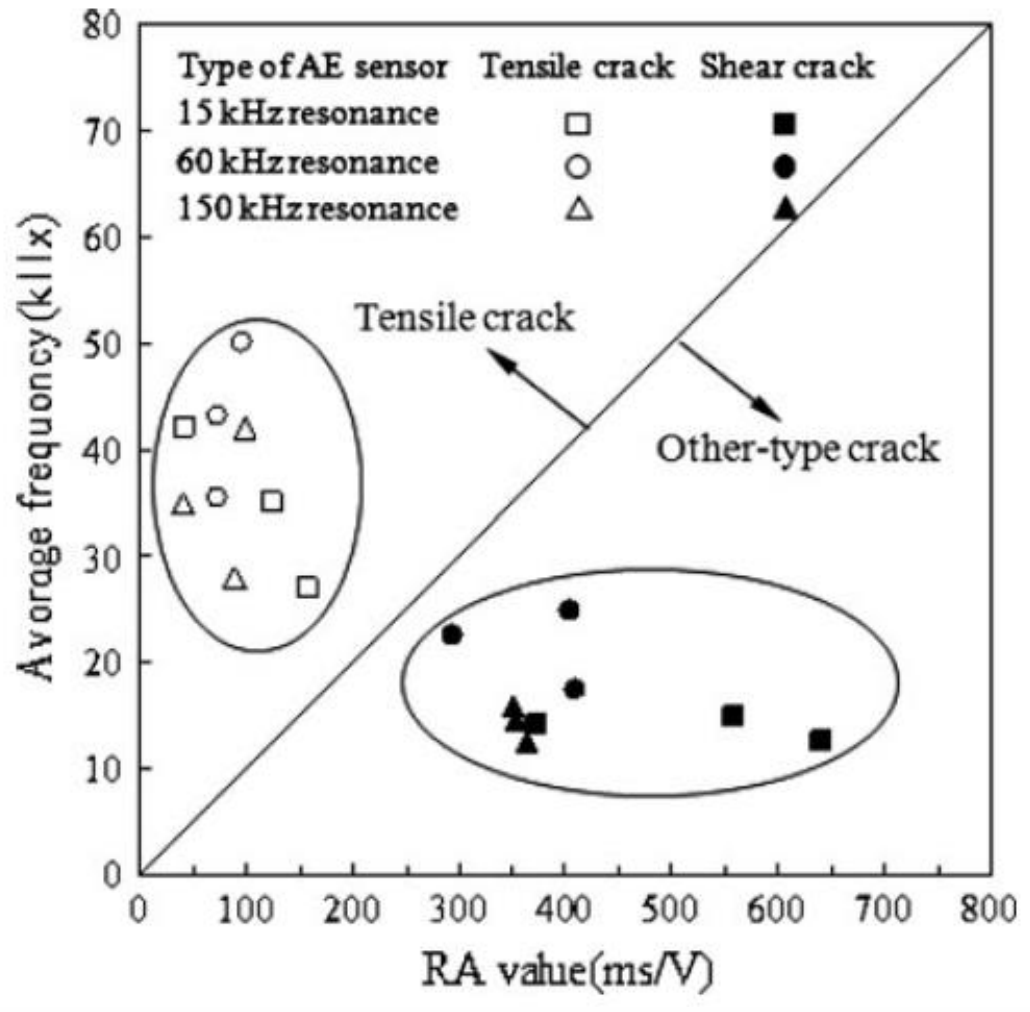

Materials and Structures DOI 10.1617/s11527-010-9640-6 


\section{CONCLUSIONS}

AE can closely monitor the fracture behavior of curved TRC specimens

The geometry (width) of the components plays a very important role, as plates exhibit much lower frequency and longer duration compared to the beams for the same fracture mechanism

This can lead to erroneous conclusions when the analysis is based on small laboratory specimens.

Future work should involve a methodology to correct for the differences or at least establish a distance within which the characterization is reliable. 
daggelis@vub.be

VRIJE

UNIVERSITEIT

BRUSSEL 